\title{
Anvisa intensifica controle de infecção em serviços de saúde
} Anvisa enhances infection control in health services

\author{
Agência Nacional de Vigilância Sanitária - Anvisa*
}

O grave e recorrente problema de saúde pública, a infecção hospitalar (IH) que acomete tanto os países desenvolvidos quanto os em desenvolvimento, está sendo enfrentado pela Agência Nacional de Vigilância Sanitária (Anvisa) a partir de uma iniciativa inédita de treinamento em massa de profissionais de saúde das vigilâncias estaduais de todo o País nas metodologias e técnicas mais avançadas de investigação de surtos em serviços de saúde.

Diante do drástico legado de mortalidade dos surtos de infecção, desde 1983 tornou-se obrigatório um órgão específico dentro dos hospitais para prevenir e controlar a IH, surgindo assim as Comissões de Controle de Infecção Hospitalar. São grandes os transtornos para a saúde pública, a instituição e os pacientes nela internados devido à significativa letalidade, sendo responsável direta ou indiretamente por elevação das taxas de morbidade e mortalidade.

Outras consequiências são o aumento do tempo de internação e dos custos decorrentes tanto para a instituição quanto para os próprios pacientes e familiares, além da ameaça constante da disseminação de bactérias multirresistentes. Isso porque, ao prolongar o tempo de internação, gera-se uma elevação no consumo de medicamentos e aumento dos custos adicionais, não só para os órgãos administrativos institucionais, bem como para os pacientes e familiares, além de retardar o retorno do paciente às suas atividades normais, muitas vezes, retorno esse com graves seqüelas. Sendo assim, se fez necessária a criação de um órgão específico dentro do hospital para prevenir e controlar a IH, surgindo então as Comissões de Controle de Infecção Hospitalar.

Um dos marcos históricos no controle das Infecções Hospitalares no Brasil aconteceu na década de oitenta, quando o Ministério da Saúde criou em março de 1983 um grupo de trabalho integrado tanto por seus representantes quanto dos Ministérios da Educação e da Previdência Social. Esse grupo elaborou um documento normativo, gerando a Portaria MS 196, de 24 de junho de 1983, determinando a todos hospitais brasileiros a constituição de uma Comissão de Controle de Infecção Hospitalar.

Como prerrogativas estão as orientações práticas sob a forma de anexos, como vigilância epidemiológica com coleta de dados, a notificação feita pelo médico ou enfermeira, treinamento em serviço, elaboração de normas técnicas, isolamento de pacientes, controle do uso de antimicrobianos, normas de seleção de germicidas e preenchimento de relatórios.

Mas somente a partir de 1985 , com a repercussão da morte do ex-presidente Tancredo Neves, em conseqüência de infecção hospitalar, essa questão assumiu uma dimensão maior, sensibilizando a população e, principalmente, os profissionais da área de saúde. Resultou dessa preocupação a realização do "Curso de Introdução ao Controle de Infecção Hospitalar", ministrado em todo o País. No mesmo ano foi publicado, o "Manual de Controle de Infecção Hospitalar", objetivando preconizar medidas de prevenção e controle das Infecções Hospitalares, adaptadas e voltadas para a realidade nacional. Outra iniciativa que merece ser destacada foi a realização do primeiro Curso de Introdução de Controle de Infecção Hospitalar para treinamento de profissionais de nível superior.

Em 1987, foi constituída, em nível nacional, uma comissão de controle de IH, com representações de vários estados e, em 6 de abril de 1988, a Portaria $\mathrm{n}^{\circ} 232$ criou o Programa Nacional de Controle de IH (PNCIH), que em 1990, transformou-se em Divisão Nacional de Controle de Infecção Hospitalar, por meio da Portaria nº 666, de 17 de maio de 1990. Em 1989, em São Paulo, ocorreu o $1^{\circ}$ Congresso Brasileiro sobre Infecção Hospitalar realizado pela Associação Paulista de Estudos e Controle de Infecção Hospitalar, com cerca de mil participantes e vários convidados estrangeiros. 
Em 27 de agosto de 1992, a Portaria 196 foi substituída pela Portaria 930, do Ministério da Saúde, representando um grande avanço no sentido de maior profissionalização na prática do controle de infecções. A Portaria determinava que todos os hospitais deveriam manter o Programa de Controle de Infecção Hospitalar, independentemente de entidade mantenedora.

Definiu ainda a estrutura de funcionamento e as áreas de competência da CCIH e criou o Serviço de Controle de Infecção Hospitalar (SCIH), sendo que as Comissões atuariam como órgãos normativos e os Serviços como órgãos executivos das ações programadas de controle de infecção. Além disso, detalharam-se os conceitos de IH e métodos de vigilância epidemiológica por meio da busca ativa dos casos, classificaramse as cirurgias quanto ao potencial de contaminação e normatizou-se a limpeza, desinfecção e esterilização de artigos e superfícies hospitalares. Após esta portaria foram criadas mais de 127 CCIHs em todo o País.

Outra iniciativa importante foi a edição da Lei Federal 9.431, de 6 de janeiro de 1997, recebida com perplexidade por todos os profissionais que trabalhavam com controle de infecção hospitalar no País, uma vez que foi vetada a maioria dos artigos, como a obrigatoriedade da existência do Serviço de Controle de Infecção Hospitalar, a composição e as competências deste e da Comissão de Controle, a obrigatoriedade da responsabilidade técnica de um farmacêutico para gestão de antimicrobianos, soluções parenterais de grande volume, germicidas e materiais médico-hospitalares.

Importante destacar o aspecto positivo da obrigatoriedade de uma Comissão de Controle de Infecção Hospitalar (CCIH) e de um Programa de Controle de Infecções Hospitalares (PCIH), definido como um conjunto de ações que visam a redução máxima possível da incidência e gravidade das infecções hospitalares.

A última portaria publicada pelo Ministério da Saúde foi a de $\mathrm{n}^{\circ} 2.616$, de 12 de maio de 1998 , que rege o controle de infecção hospitalar e mantém a obrigatoriedade de um Programa de Controle de Infecções Hospitalares em todos os hospitais do país. Pela norma, fica a cargo dos integrantes do Serviço de Controle de Infecção Hospitalar (SCIH) a função de membros-executores as ações programadas de controle de infecção hospitalar, sendo que estes passam a ser membros consultores, ou seja, representantes dos vários serviços do hospital.

A portaria define ainda as características desejáveis de formação dos profissionais e parâmetros para determinação do número dos membros executores da $\mathrm{CCIH}$, com base no número de leitos e tipos de unida- de de que se compõe o hospital. Outro aspecto importante dessa medida é a atribuição das competências para a Coordenação de Controle de Infecção Hospitalar do Ministério da Saúde e para as Coordenações de Controle de Infecção Hospitalar Estaduais, Distritais e Municipais. Aborda ainda conceitos e critérios para os diagnósticos das infecções hospitalares, orientações sobre a vigilância epidemiológica e seus indicadores epidemiológicos, lavagem das mãos e recomendações sobre normas de limpeza, desinfecção e esterilização, uso de germicidas, microbiologia, lavanderia e farmácia.

Em 15 de maio de 1999, o Ministério da Saúde decretou o Dia Nacional do Controle de Infecção Hospitalar, visando a uma maior conscientização de toda classe de profissionais de saúde, bem como todos os demais envolvidos, para diminuir a incidência de óbitos provocados pelo problema. Nessa mesma data, no ano de 1847 , na Hungria, o médico-obstetra Ignaz P. Semmelweiss defendeu e incorporou a prática da lavagem de mãos como atitude obrigatória dos enfermeiros e médicos que entravam nas enfermarias. Uma simples, mas eficiente iniciativa que conseguiu reduzir a taxa de mortalidade de pacientes de $18 \%$ para $1,5 \%$. Foi por esse motivo, que o dia 15 de maio tornou-se uma data tão importante e significativa para nós.

Atualmente, as diretrizes gerais para o Controle das Infecções em Serviços de Saúde são delineadas pela Agência Nacional de Vigilância Sanitária, que foi criada em 26 de janeiro de 1999. A transferência do programa para a Anvisa, associada à ação da vigilância sanitária de serviços de saúde, fortaleceu tanto o programa quanto o Sistema Nacional de Vigilância Sanitária.

A integração e ampliação das ações do programa de forma matricial nas diversas ações do Programa de Vigilância Sanitária de Produtos e Serviços são fundamentais para enfrentar o problema dos eventos adversos. É fundamental o fortalecimento dos mecanismos de incorporação das ações de prevenção e controle das infecções pelas vigilâncias sanitárias de serviços de saúde nas três esferas de gestão, inclusive com a união dos programas na instância federal. Essa nova estrutura poderá potencializar o impacto das ações, já que o Programa de Prevenção e Controle das Infecções Hospitalares e o de Vigilância Sanitária de Produtos e Serviços são interdependentes.

Outra iniciativa importante é a interação do controle de infecções com a regulação de medicamentos, principalmente o que diz respeito ao controle da resistência microbiana. É necessária a definição de diretrizes de registro de medicamentos para assegurar um controle mais efetivo do mercado, favorecendo a redução 
da resistência e a manutenção da atividade antimicrobiana dos medicamentos.

A ampliação da abrangência das ações de prevenção e controle das infecções hospitalares para os demais serviços de saúde poderá alterar o foco da vigilância sanitária, que avança da análise dos aspectos estruturais e organizacionais da comissão para a valorização da prevenção e controle de risco e o alcance de resultados na redução da freqüência e gravidade das infecções.

O aumento da descentralização das ações de vigilância sanitária, por meio da capacitação dos estados e municípios, redundará em maior número de investigações das infecções e eventos adversos graves em serviços de saúde, com metodologia padronizada e que retroalimente as ações de regulação de produtos e serviços. Outra frente que merece ser consolidada é a ampliação dos estudos e pesquisas direcionados, possibilitando decisões e intervenções mais ágeis e efetivas, seja preventivamente ou mesmo no enfrentamento do problema.

Em 4 de junho de 2003, por meio da Portaria n 385 , a Unidade de Controle de Infecção em Serviços de Saúde assume nova dimensão política, passando a ser intitulada Gerência de Investigação e Prevenção das Infecções e dos Eventos Adversos (GIPEA), associando-o à vigilância sanitária de serviços de saúde, com o objetivo de fortalecer tanto o programa quanto o Sistema Nacional de Vigilância Sanitária.

Atualmente a metodologia de planejamento, implantação e avaliação técnica e financeira das ações já integram parte da rotina dos gerentes e gestores públicos. Mas faz-se ainda necessária a integração e a ampliação das ações do programa de forma matricial nas diversas ações do Programa de Vigilância Sanitária de Produtos e Serviços.

A meta é ampliar ao máximo a divulgação de informações e publicações relativas ao controle de infecções e iatrogenias em serviços de saúde, elaboração e padronização de indicadores, bem como o monitoramento das infecções e os eventos adversos em serviços de saúde. Além disso, deve-se realizar a investigação da ocorrência de eventos adversos em serviços de saúde e o desenvolvimento de atividades junto a outros órgãos da administração federal, estadual, distrital e municipal, inclusive os de defesa do consumidor, na tentativa de exercer o efetivo cumprimento da legislação. Entre as ações em curso da Gerência, destacam-se as investigações de surtos de endoftalmite relacionado a cirurgias de catarata, Rotavírus, prótese mamária, implantes ortopédicos, in- fecções relativas à Nutrição Parenteral Total, infecções por $P$. aeruginosa, Bário, entre outros.

Para conhecer a situação das comissões de controle de infecção nos hospitais (CCIH) brasileiros e, assim, definir estratégias de aperfeiçoamento da prevenção e investigação das infecções, a Anvisa firmou parceria com a Faculdade de Saúde Pública da Universidade de São Paulo para realização da maior pesquisa feita até hoje no Brasil na área. "É uma radiografia do funcionamento das CCIHs", diz a coordenadora da pesquisa, a professora Regina Alves. O estudo envolveu $61,3 \%$ (4.118) dos hospitais brasileiros, em todos os estados do País; hospitais públicos e privados; de atendimento geral, especializado e com especialidades e foi o mais complexo estudo já realizado até hoje. O último estudo sobre o assunto foi realizado pelo Ministério da Saúde em 1994.

Os resultados mostraram que $76,1 \%$ dos hospitais têm comissão de controle de infecção formalmente nomeada e apenas $3 \%$ deles não realizam vigilância epidemiológica das infecções, o que pode dificultar a investigação dos casos e a adoção de medidas corretivas. Dentre os $72,6 \%$ que investigam os casos de infecção, 81,3\% utilizam como método a busca ativa dos casos, processo de detecção recomendado pelo Ministério da Saúde.

Os questionários foram encaminhados para as comissões estaduais, que distribuíram os formulários para os hospitais. "Esperamos ter a taxa de infecção fidedigna, baseada no perfil do hospital e daquela área analisada", acredita Regina. As duas últimas etapas da pesquisa avaliaram o funcionamento das comissões nos municípios, a prevalência de infecções e a qualidade das ações de prevenção nas unidades de terapia intensiva.

Devido ao alto custo, poucos hospitais no País têm sistema informatizado para auxiliar no registro das ocorrências de infecção, o restante registra os casos manualmente. Para resolver esse problema e uniformizar os dados, a Anvisa desenvolveu um sistema que será disponibilizado gratuitamente a todos os serviços de saúde.

O Sistema Nacional de Informação para Controle de Infecções em Serviços de Saúde (Sinaiss) está em fase de consolidação e pretende assegurar um banco de dados nacional, em que as taxas de IH de todos os hospitais estarão discriminadas por tipo, esfera, número de leitos, oferecendo informações sobre taxas de infecção nacionais, por hospital, município e estado. O Sinaiss é uma ferramenta para monitorar os indicadores dentro dos recursos mais modernos em con- 
trole de infecção, facilitando a notificação por meio de procedimentos de rotina e linguagem simples.

Foram publicados no ano passado os Manuais de Microbiologia módulos II e III. Os Manuais de Lavanderia hospitalar, Processamento de Artigos e Superfícies, Higienização das Mãos, Biossegurança estão em fase de revisão e atualização. Outras iniciativas que merecem destaque são o Curso de Investigação Epidemiológica para profissionais que atuam nos Serviços de Vigilância Sanitária estaduais, municipais e Distrital do Brasil; elaboração de Resolução sobre a reutilização de materiais hospitalares, no momento em Consulta Pública no sítio da Anvisa; elaboração de pareceres e notas técnicas relacionados à Área de Epidemiologia Hospitalar; apoio a eventos técnicos e capacitações.

Três significativos e oportunos convênios com a Anvisa estão em andamento. Entre eles, destaca-se o Curso de Educação à Distância em Controle de Infecção Hospitalar para profissionais que atuam nos Serviços de Vigilância Sanitária estadual, municipal e distrital no Brasil, em parceria com a Universidade
Federal de São Paulo (Unifesp). Trata-se de estudo da dinâmica de contaminação extrínseca de anti-sépticos, durante as etapas de aquisição, estocagem, manipulação, distribuição e uso em serviços de saúde do projeto hospitais sentinelas, com a finalidade de identificar os fatores de risco e orientar as ações de prevenção de infecções, com apoio da Fundação de Desenvolvimento da Pesquisa de Minas Gerais.

Outro convênio relacionado ao controle de infecções prevê o estudo de um dia de prevalência de infecção relacionada à assistência em Unidades de Terapia Intensiva, em conjunto com a Faculdade de Saúde Pública da Universidade de São Paulo (USP). Para completar, será promovido o Curso de Especialização em Epidemiologia para serviços hospitalares vinculado à Universidade Federal do Rio Grande do Norte voltado aos profissionais de vigilância sanitária que atuam nos estados e municípios, conquistas que pretendem beneficiar profissionais de saúde, vigilância sanitária e, principalmente, os pacientes, que serão agraciados com a redução dos índices de infecção hospitalar em todo o País. 